\title{
Optimizing conditions for hot water extraction of banana juice using response surface methodology $(\mathbf{R S M})$.
}

\begin{abstract}
A response surface methodology (RSM) was used for the determination of optimum extraction temperature and time to produce an acceptable banana juice extract. Banana juice was extracted using hot water extraction method at different extraction temperature (35-95 C) and time (30-120 $\mathrm{min})$. The effects of the extraction conditions on juice yield, total soluble solids (Brix), banana odour and taste were studied by employing a second-order central composite design. The coefficient of determination, R2, for juice yield, total soluble solids (Brix), banana odour and taste were greater than 0.900. Analysis of the regression coefficients showed that temperature was the most important factor that affected characteristics of the banana juice extract as it exerted a highly significant influence ( $\mathrm{p}<$ 0.001) on all the dependent variables. An increase in extraction time and temperature of hot water extraction resulted in an increase in juice yield, total soluble solids, banana odour and taste of the banana extract. Based on surface and contour plots, optimum conditions for hot water extraction of banana juice were $95 \mathrm{C}$ for $120 \mathrm{~min}$.
\end{abstract}

Keyword: Banana juice, Hot water extraction, Response surface methodology 